07

\title{
Постростовые технологии каскадных фотоэлектрических преобразователей на основе $A^{3} B^{5}$-гетероструктур
}

\author{
() А.В. Малевская, Н.Д. Ильинская, Ю.М. Задиранов, А.А. Блохин, Д.А. Малевский, П.В. Покровский \\ Физико-технический институт им. А.Ф. Иофрфе РАН, \\ 194021 Санкт-Петербург, Россия \\ e-mail: amalevskaya@mail.ioffe.ru
}

Поступило в Редакцию 8 июля 2021 г.

В окончательной редакции 25 августа 2021 г.

Принято к публикации 31 августа 2021 г.

Проведены исследования и разработки постростовых технологий изготовления каскадных фотоэлектрических преобразователей на основе гетероструктуры GaInP/GaInAs/Ge. Рассмотрены этапы формирования антиотражающего покрытия, омических контактов и разделительной меза-структуры. Исследована технология травления контактного слоя $n^{+}$-GaAs c использованием методов плазмохимического, жидкостного химического и ионно-лучевого травления. Коэффициент отражения излучения от поверхности гетероструктуры с антиотражающим покрытием $\mathrm{TiO}_{x} / \mathrm{SiO}_{2}$ (при $x$, близком к 2) составил менее $3 \%$ в диапазоне длин волн 450-850 $\mathrm{mm}$. Величина контактного переходного сопротивления омических контактов $n$ - и р-типов проводимости составила $3 \cdot 10^{-5}-3 \cdot 10^{-6} \Omega \mathrm{cm}^{2}$, достигнуто снижение степени затенения фоточувствительной области при увеличенной проводимости контактных шин. Снижены токи утечки по поверхности мезаструктуры до величин $10^{-9}$ А при напряжении менее $1 \mathrm{~V}$.

Ключевые слова: фотоэлектрические преобразователи, омические контакты, антиотражающее покрытие, мезаструктура.

DOI: $10.21883 / J T F .2022 .01 .51859 .210-21$

\section{Введение}

Развитие концентраторной солнечной энергетики имеет большое значение в энергетической промышленности за счет высокой экологичности и эффективности преобразования солнечного излучения в электроэнергию. Широкий интерес к использованию каскадных фотоэлектрических преобразователей (ФЭП) обусловлен высокими значениями эффективности: достигнут КПД 47\% для шести каскадных $\mathrm{A}^{3} \mathrm{~B}^{5}$-элементов при преобразовании концентрированного солнечного излучения (АМ 1,5) [1-3].

Одним из основных этапов формирования ФЭП является проведение постростовой обработки гетероструктур, включающей формирование антиотражающего покрытия, омических контактов и разделительной мезаструктуры [4,5]. Исследования и разработки отдельных технологических этапов позволяют уменьшить оптические и омические потери при преобразовании солнечного излучения, а также увеличить эффективность и срок эксплуатации ФЭП.

\section{1. Гетероструктура GalnP/GalnAs/Ge}

Исследования и разработки постростовой технологии формирования каскадных ФЭП проводились на основе гетероструткуры $\mathrm{GaInP} / \mathrm{GaInAs} / \mathrm{Ge}$, включающей верхний субэлемент GaInP, средний субэлемент GaInAs, брегговский отражатель, буферный слой GaInAs, ниж- ний субэлемент Ge, выращенной на германиевой подложке $p$-типа проводимости (рис. 1). Рост верхнего субэлемента GaInP завершается формированием широкозонного окна $\mathrm{Al}_{0.52} \mathrm{In}_{0.48} \mathrm{P}$ и контактного слоя $n^{+}-\mathrm{GaAs}$, необходимого для снижения переходного контактного сопротивления фронтального омического контакта.

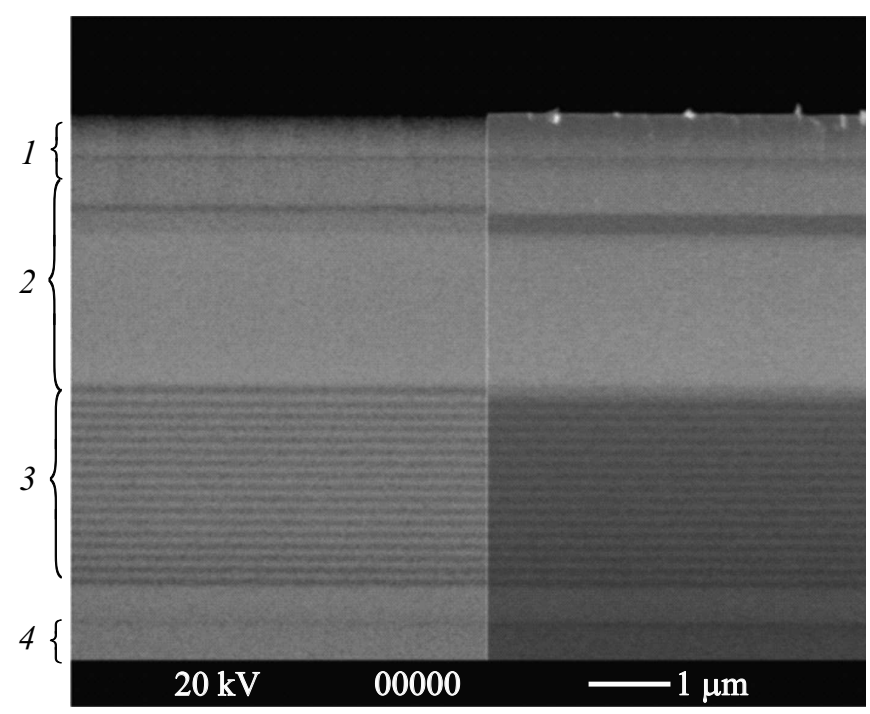

Рис. 1. Изображение скола слоев гетероструктуры $\mathrm{GaInP} / \mathrm{GaInAs} / \mathrm{Ge}$, выполненное на сканирующем электронном микроскопе: 1 - субэлемент GaInP, 2 - субэлемент GaInAs, 3 - брэгговский отражатель, 4 - субэлемент Ge. 


\section{2. Постростовые технологии формирования ФЭП}

Постростовой технологический маршрут изготовления ФЭП включает операции по проведению фотолитографии для создания рисунка в фоторезисте заданной топологии, формированию антиотражающего покрытия, омических контактов и травлению разделительной мезаструктуры. Последовательность технологических операций задается с учетом состава гетероструктуры и топологии прибора. Оптимизация маршрута обеспечивает увеличение технологичности и надежности постростовой обработки. В настоящей работе проведены разработка и оптимизация технологического маршрута, включающего следующие основные этапы:

- травление контактного слоя $n^{+}$-GaAs в местах, свободных от области фронтального омического контакта, и формирование антиотражающего покрытия (АОП) путем осаждения слоев $\mathrm{TiO}_{x} / \mathrm{SiO}_{2}$ через маску фоторезиста;

- формирование фронтального омического контакта через маску фоторезиста путем напыления слоев $\mathrm{Au}(\mathrm{Ge}) / \mathrm{Ni} / \mathrm{Au}$;

- формирование сплошного тыльного омического контакта путем напыления слоев $\mathrm{Ag}(\mathrm{Mn}) / \mathrm{Ni} / \mathrm{Au}$;

- электрохимическое утолщение омических контактов;

- создание разделительной мезаструктуры путем травления слоев гетероструктуры и подложки.

\section{3. Антиотражающее покрытие}

Формирование АОП на фоточувствительной области ФЭП обеспечивает снижение коэффициента отражения солнечного излучения. Для минимизации коэффициента отражения в широком диапазоне солнечного спектра используются многослойные покрытия, например на основе слоев $\mathrm{TiO}_{x}$ (при $x$, близком к 2), $\mathrm{SiO}_{2}, \mathrm{Si}_{3} \mathrm{~N}_{4}[6]$. На параметры антиотражающего покрытия оказывает влияние состояние поверхности ФЭП. Для достижения хорошей адгезии АОП к поверхности полупроводниковой структуры при минимальном коэффициенте отражения солнечного излучения проведены исследования по подготовке поверхности ФЭП.

Для открытия фоточувствительной области гетероструктуры проводится локальное стравливание контактного слоя $n^{+}$-GaAs в местах, свободных от области фронтального омического контакта селективно до широкозонного окна $\mathrm{Al}_{0.52} \operatorname{In}_{0.48} \mathrm{P}$. Выполнены исследования технологии плазмохимического, жидкостного химического и ионно-лучевого травления контактного слоя гетероструктуры.

Плазмохимическое травление контактного слоя $n^{+}$-GaAs селективно до стоп-слоя $\mathrm{Al}_{0.52} \operatorname{In}_{0.48} \mathrm{P}$ проводится в плазме $\mathrm{BCl}_{3}$ и $\mathrm{SF}_{6}$. Основным преимуществом плазмохимического травления является высокая точность задания топологии ФЭП за счет анизотропности процесса и отсутствия бокового подтравливания под маску фоторезиста. Для удаления нарушенного слоя после плазмохимического травления предлагается проводить обработку поверхности методом жидкостного химического травления на глубину менее $100 \mathrm{~nm}$ в сильно разбавленных составах на основе перекиси водорода с добавлением ортофосфорной или серной кислоты.

При использовании метода жидкостного химического травления контактного слоя $n^{+}$-GaAs высокой селективностью к стоп-слою $\mathrm{Al}_{0.52} \operatorname{In}_{0.48} \mathrm{P}$ обладают травители на основе лимонной кислоты и перекиси водорода, а также на основе аммиака и перекиси водорода. Однако из-за изотропности свойств жидкостного травления наблюдается затрав контактного слоя $n^{+}$-GaAs под область фоторезиста, что ведет к снижению точности задания топологии ФЭП.

Кроме того, особенностью жидкостного химического травления является процесс образования на поверхности гетероструктуры слоя естественного окисла после химической обработки и промывки деионизованной водой. Толщина и состав естественного окисла зависят от состава используемого травителя. Для увеличения качества поверхности гетероструктуры предлагается проводить дополнительную обработку методом ионно-лучевого травления в среде $\mathrm{Ar}$ для очистки структуры и удаления слоя окисла непосредственно перед осаждением АОП. При варьировании ускоряющего напряжения $(U)$ получены разные скорости травления $(V)$ поверхности широкозонного окна $\mathrm{Al}_{0.52} \operatorname{In}_{0.48} \mathrm{P}$ и соответственно разные состояния поверхности: $U=100 \mathrm{~V}, V=0.3 \AA / \mathrm{s}$; $U=300 \mathrm{~V}, V=0.8 \AA / \mathrm{s}$.

Проведено исследование влияния параметров травления на коэффициент отражения солнечного излучения от поверхности гетероструктуры с нанесенным АОП на основе слоев $\mathrm{TiO}_{x} / \mathrm{SiO}_{2}$. Было установлено, что состав травителей и режимы процесса не оказывают существенного влияния на величину коэффициента отражения солнечного излучения в рабочем диапазоне длин волн ФЭП. При введении дополнительной ионной обработки непосредственно перед осаждением АОП наблюдается увеличение коэффициента отражения на $0.1 \%$ при $U=100 \mathrm{~V}$ и на $0.2 \%$ при $U=300 \mathrm{~V}$. Однако очистка поверхности оказывает существенное влияние на адгезию АОП к поверхности гетероструктуры, и увеличением коэффициента отражения на доли процента можно пренебречь.

Наиболее технологичными и оптимальными методами подготовки фоточувствительной области ФЭП с точки зрения передачи заданной топологии, скорости травления контактного слоя $n^{+}-\mathrm{GaAs}$ и высокой адгезии АОП являются следующие:

- метод плазмохимического травления с удалением нарушенного слоя в сильно разбавленном травителе на основе перекиси водорода и серной кислоты; 


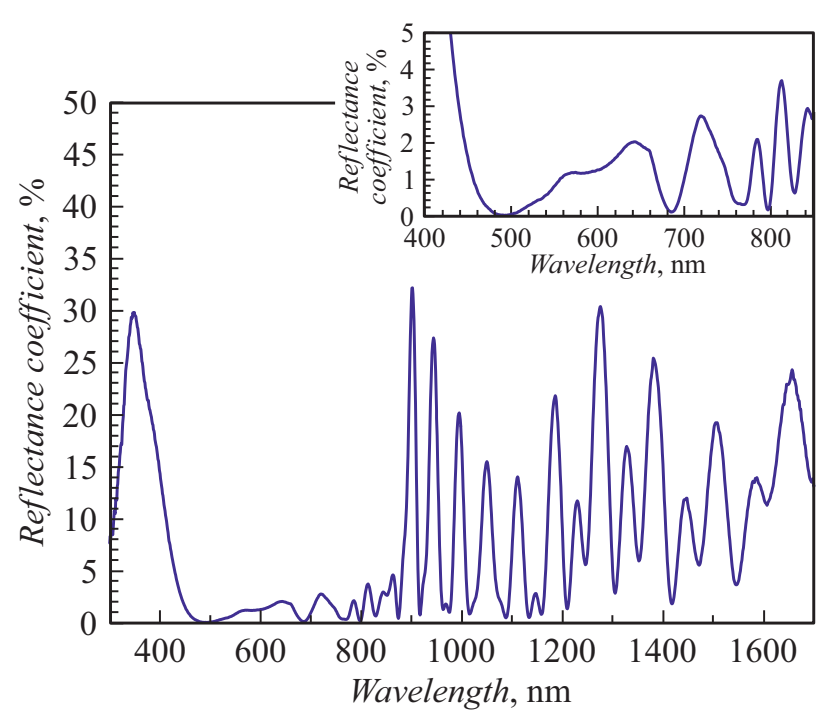

Рис. 2. Спектральная характеристика коэффициента отражения солнечного излучения от поверхности гетероструктуры $\mathrm{GaInP} / \mathrm{GaInAs} / \mathrm{Ge}$ c AOП $\mathrm{TiO}_{x} / \mathrm{SiO}_{2}$.

- метод жидкостного химического травления в сильноразбавленном травителе на основе $\mathrm{NH}_{4} \mathrm{OH}+\mathrm{H}_{2} \mathrm{O}_{2}$ с дополнительной обработкой ионным пучком при $U=100 \mathrm{~V}$.

В обоих методах достигнут коэффициент отражения менее 3\% в диапазоне длин волн 450-850 nm - в области чувствительности верхних двух субэлементов (рис. 2). Следует отметить, что чувствительность германиевого субэлемента находится в диапазоне длин волн 950-1600 nm, и так как ток, вырабатываемый германиевым субэлементом, превышает ток верхних двух субэлементов на 20-30\% [7], то основные требования по снижению коэффициента отражения накладываются на диапазон длин волн 350-950 $\mathrm{nm}$.

\section{4. Омические контакты}

Разработка и оптимизация технологии формирования омических контактов ФЭП обеспечивает снижение омических потерь при преобразовании солнечного излучения в электроэнергию [8-10]. При концентрировании солнечного излучения более $500 \times$ плотность фототока превышает $10 \mathrm{~A} / \mathrm{cm}^{2}$. Для увеличения эффективности работы ФЭП в таких условиях необходимо снизить переходное контактное сопротивление и повысить электрическую проводимость контактных шин, что приводит к увеличению токосъема с элемента и обеспечивает теплоотвод.

Использование контактной системы на основе слоев $\mathrm{Au}(\mathrm{Ge}) / \mathrm{Ni} / \mathrm{Au}$ в качестве фронтального омического контакта позволяет получить низкое контактное сопротивление порядка $3-5 \cdot 10^{-6} \Omega \mathrm{cm}^{2}$ к слою $n^{+}$-GaAs. Формирование тыльного омического контакта на основе слоев $\mathrm{Ag}(\mathrm{Mn}) / \mathrm{Ni} / \mathrm{Au}$ к германиевой подложке $p$-типа проводимости обеспечивает сопротивление менее $3-5 \cdot 10^{-5} \Omega \mathrm{cm}^{2}$. Для увеличения электрической проводимости контактных шин используется технология электрохимического наращивания омических контактов путем осаждения контактных материалов на основе золота или серебра [11].

Наращивание омических контактов осуществляется через маску фоторезиста. Формирование вертикальных стенок профиля маски является оптимальным для создания контактных шин, обеспечивающих максимальную электрическую проводимость контакта, при минимальных оптических потерях, обусловленных затенением фоточувствительной области ФЭП.

Широко используемым электролитом для осаждения золота является цианистый электролит золочения. Осаждение золота ведется при температуре 50-60 ${ }^{\circ}$, и при использовании данного электролита происходит разрушение маски под воздействием повышенной температуры, а также ионов $\left(\mathrm{CN}^{-}\right)$, что вызывает нарушение адгезии фоторезиста к поверхности полупроводника и разрастание золота на фоточувствительную область ФЭП. Увеличение ширины контактных шин ведет к возрастанию оптических потерь. Для снижения степени разрастания контакта осаждение золота можно проводить через двуслойную маску, включающую диэлектрический подслой и слой фоторезиста. Изоляция проводящей поверхности полупроводниковой гетероструктуры обеспечивает снижение напряжения на гетерогранице полупроводник/маска/электролит, не происходит отслоение фоторезиста от поверхности полупроводника и рост золотого осадка осуществляется по профилю маски (рис. 3,a).

Для электрохимического осаждения серебра можно использовать железосинеродистый электролит серебрения. Использование данного электролита не ведет к разрушению маски фоторезиста, что обусловлено высокой пластичностью серебра и проведением процесса осаждения при комнатной температуре. Электрохимический рост серебра проводится в соответствии с профилем маски фоторезиста и обеспечивает возможность формирования контактных шин с вертикальной боковой стенкой повышенной толщины $(4-7 \mu \mathrm{m})$ без увеличения степени затенения фоточувствительной области ФЭП (рис. $3, b)$. Полученная топология и низкое удельное сопротивление серебра $\left(0.015-0.016 \Omega \mathrm{mm}^{2} / \mathrm{m}\right)$ обеспечивают увеличение проводимости контактов при минимальных оптических потерях на затенение.

\section{5. Мезаструктура}

Формирование мезаструктуры проводится для разделения всей площади гетероструктуры на чипы ФЭП. Полупроводниковая многослойная гетероструктура на основе GaInP/GaInAs/Ge включает в состав набор тонких слоев, обладающих различными физико-химическими свойствами, что создает определенные сложности в 


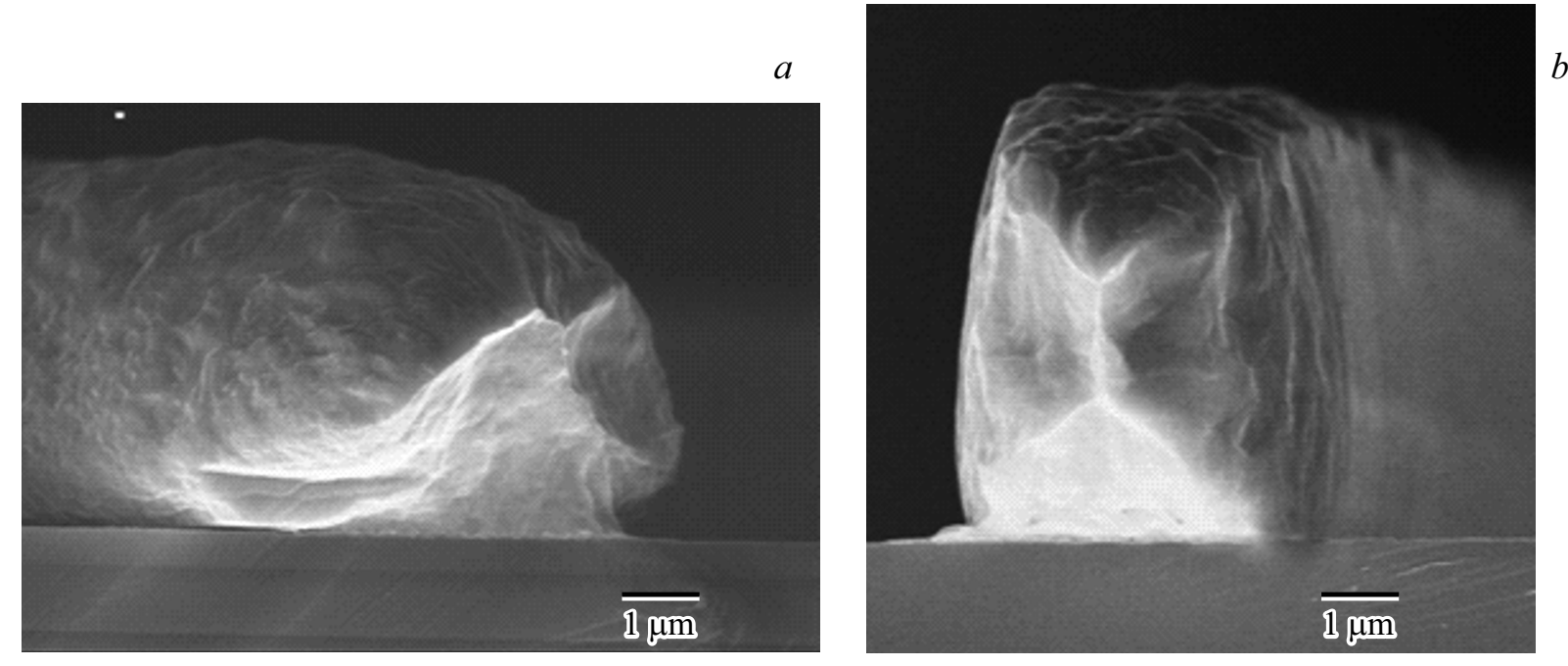

Рис. 3. Изображение со сканирующего электронного микроскопа скола контактных шин после электрохимического осаждения золота $(a)$ и серебра $(b)$.

процессе травления. В настоящей работе исследованы технологии травления гетероструктуры с использованием изотропных и анизотропных методов.

К изотропным методам относятся жидкостное химическое и электрохимическое травления. Недостатком изотропных методов является боковое подтравливание гетероструктуры под маску фоторезиста, что может затруднить процесс пассивации боковой стенки мезы диэлектрическим покрытием. Различия скоростей травления разных по химическим свойствам слоев может приводить к возникновению протравов по тонким слоям, что ведет к необходимости разработки новых травителей при изменении состава гетероструктуры. Однако широкий спектр химических реактивов обеспечивает возможность разработки технологии формирования мезы различных гетероструктур [12].

Высокотехнологичным методом травления слоев гетероструктуры GaInP/GaInAs/Ge является разработанная двустадийная методика. На первой стадии проводится травление слоев GaInP/GaInAs селективно до германиевой подложки в составе: $\mathrm{K}_{2} \mathrm{Cr}_{2} \mathrm{O}_{7}, \mathrm{HBr}, \mathrm{H}_{3} \mathrm{PO}_{4}$; на второй стадии травление Ge. Проведены исследования различных способов травления германиевой подложки:

- в сильноразбавленном травителе на основе бромистоводородной кислоты и перекиси водорода;

- в травителе на основе ортофосфорной кислоты и перекиси водорода;

- методом электрохимического травления в слабощелочном электролите на основе глицерина.

Сильноразбавленный травитель $\left(\mathrm{HBr}, \mathrm{H}_{2} \mathrm{O}_{2}\right)$ обладает очень низкой скоростью травления (менее $0.1 \mu \mathrm{m} / \mathrm{min}$ ) и является очень чувствительным к наличию металлических частиц в растворе, что ведет к низкой технологичности и надежности процесса из-за возможности образования протравов по отдельным слоям гетерострук- туры. В травителе $\left(\mathrm{H}_{3} \mathrm{PO}_{4}, \mathrm{H}_{2} \mathrm{O}_{2}\right)$ и в слабощелочном электролите на основе глицерина скорость травления составляет порядка $1 \mu \mathrm{m} / \mathrm{min}$, отсутствуют дефекты по боковой поверхности мезы.

К анизотропным методам травления относится технология плазмохимического травления $[13,14]$. Травление слоев гетероструктуры $\mathrm{GaInP} / \mathrm{GaInAs} / \mathrm{Ge}$ для формирования разделительной мезаструктуры проводилось в плазме трихлорида бора $\left(\mathrm{BCl}_{3}\right)$ на установке плазмохимического травления STE ICP 200e (SemiTEq) в комбинированной плазме индуктивного и емкостного разряда (ICP/RIE) с последующим удалением нарушенного слоя методом жидкостного химического травления.

Для анализа влияния методов формирования мезаструктуры на параметры ФЭП проведено измерение темновых вольт-амперных характеристик при точности измерения темнового тока $10^{-12} \mathrm{~A}$ (рис. 4). При использовании метода жидкостного химического травления величина тока утечки составляет менее $10^{-9} \mathrm{~A}$ при напряжении менее $1 \mathrm{~V}$ (рис. 4, кривая 2), однако наблюдается большой разброс параметров по площади гетероструктуры. Использование метода плазмохимического травления ведет к небольшому возрастанию тока утечки (рис. 4, кривая 1) из-за образования нарушенного слоя, при удалении которого достигнуто уменьшение тока утечки до величины менее $10^{-9}$ А при напряжении менее $1 \mathrm{~V}$ (рис. 4, кривая 3).

\section{Заключение}

Проведены исследования и разработки различных этапов постростовой обработки $\mathrm{A}^{3} \mathrm{~B}^{5}$ гетероструктур. Исследованы этапы формирования АОП, включающие травление контактного слоя $n^{+}$-GaAs и очистку поверхности непосредственно перед осаждением слоев 


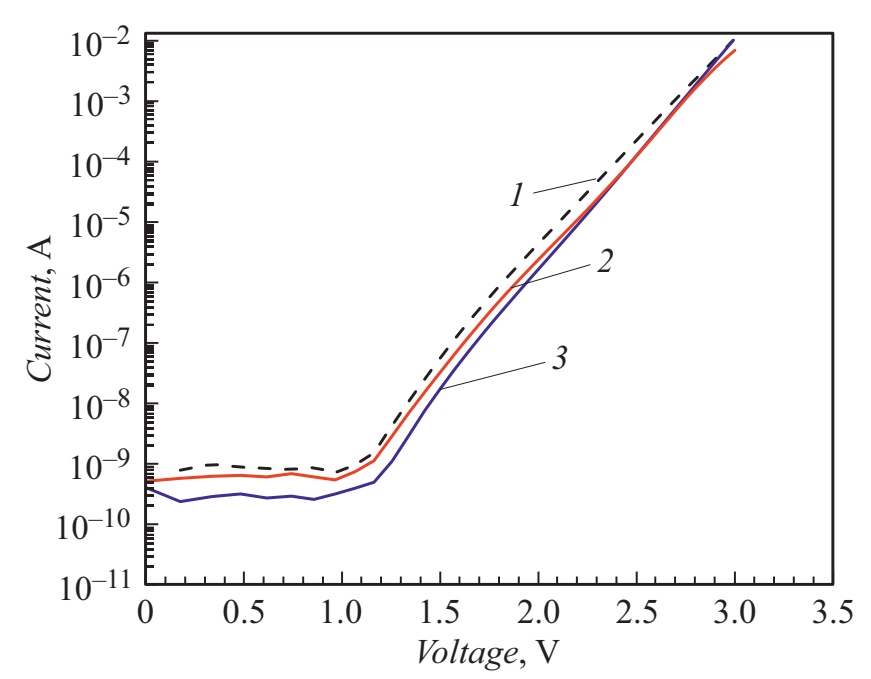

Рис. 4. Темновая вольт-амперная характеристика ФЭП после формирования разделительной мезы: 1 - плазмохимическое травление, 2 - жидкостное химическое травление, 3 - плазмохимическое травление + удаление нарушенного слоя.

$\mathrm{TiO}_{x} / \mathrm{SiO}_{2}$. Достигнуто снижение коэффициента отражения солнечного излучения от поверхности гетероструктуры с АОП до величины менее $3 \%$ в диапазоне длин волн 450-850 nm. Выполнены разработки контактных систем для формирования утолщенных омических контактов на основе серебра с низкой степенью затенения фоточувствительной области ФЭП при повышенной проводимости контактных шин. Разработана технология формирования разделительной мезаструктуры методами жидкостного-химического и плазмохимического травления, достигнуто уменьшение тока утечки до величины менее $10^{-9}$ А при напряжении менее $1 \mathrm{~V}$.

\section{Конфликт интересов}

Авторы заявляют, что у них нет конфликта интересов.

\section{Список литературы}

[1] Zh.I. Alferov, V.M. Andreev, V.D. Rumyantsev. Concentrator Photovoltaics, ed. by A. Luque, V. Andreev. Springer Ser. in Optical Sciences (Springer, Berlin-Heidelberg, 2007), v. 130, p. 25. DOI: 10.1007/978-3-540-68798-6_2

[2] M.A. Green, E.D. Dunlop, J. Hohl-Ebinger, M. Yoshita, N. Kopidakis, X. Hao. Prog. Photovolt. Res. Appl., 29 (1), 3 (2020). DOI: $10.1002 /$ pip.3371

[3] H. Apostoleris, M. Stefancich, M. Chiesa. Concentrating photovoltaics $(C P V)$ : the path ahead. $1^{\text {st }}$ ed. (Springer, 2018)

[4] У. Моро. Микролитография (Мир, М., 1990)

[5] H.J. Levinson. Principles of lithography. $3^{\text {rd }}$ ed. (Washington, SPIE, 2010), p. 504.

[6] А.В. Малевская, Ю.М. Задиранов, А.А. Блохин, В.М. Андреев. Письма в ЖТФ, $45(20), 15$ (2019).

DOI: 10.21883/PJTF.2019.20.48386.17916
[7] Н.А. Калюжный, А.С. Гудовских, В.В. Евстропов, B.М. Лантратов, С.А. Минтаиров, Н.Х. Тимошина, М.З. Шварц, В.М. Андреев. ФТП, 44 (11), 1568 (2010).

[8] О.К. Мокеев, А.С. Романцев. Химическая обработка и фотолитография в производстве полупроводниковых приборов и микросхем (Высшая школа, М., 1979)

[9] Microlithography. Science and Technology, ed. by B.W. Smith, K. Suzuki. $2^{\text {nd }}$ ed. (Taylor \& Francis Group, 2007)

[10] M.E. Levinshtein. Semiconductor Technology (Wiley-Interscience publication, USA, 1997)

[11] A.V. Malevskaya, D.A. Malevski, N.D. Il'inskaya. J. Phys. Conf. Ser., 690 (1), 012039 (2016).

[12] А.В. Малевская, Н.Д. Ильинская, В.М. Андреев. Письма в ЖТФ, 45 (24), 14 (2019). DOI: 10.21883/PJTF.2019.24.48795.17953

[13] Д.И. Соловецкий. Механизмы плазмохимического травления материалов. Энциклопедия низкотемпературной плазмы. Книга III (Наука, М., 2000)

[14] M. de Lafontaine, E. Pargon, C. Petit-Etienne, G. Gay, A. Jaouad, M.-J. Gour, M. Volatier, S. Fafard, V. Aimez, M. Darnon. Sol. Energ. Mat. Sol. C., 195, 49 (2019). DOI: $10.1016 /$ j.solmat.2019.01.048 